\title{
Anatomia encefálica comparativa de primatas humanos e não-humanos: uma revisão
}

\author{
Comparative brain anatomy of human and non-human primates: a review \\ Anatomía comparativa del cerebro de primates humanos y no humanos: una revisión
}

Recebido: 28/01/2021 | Revisado: 02/02/2021 | Aceito: 04/02/2021 | Publicado: 10/02/2021

\author{
Dayane Kelly Sabec Pereira \\ ORCID: https://orcid.org/0000 -0002-8886-4668 \\ Universidade Federal de Goiás, Brasil \\ E-mail: daya_ks@hotmail.com \\ Eugênio Gonçalves de Araújo \\ ORCID: https://orcid.org/0000-0002-0242-2827 \\ Universidade Federal de Goiás, Brasil \\ E-mail: earaujo65@live.com \\ Kleber Fernando Pereira \\ ORCID: https://orcid.org/0000-0002-5102-6273 \\ Universidade Federal de Goiás, Brasil \\ E-mail: kleber.ufpr@gmail.com \\ Valcinir Aloisio Scalla Vulcani \\ ORCID: https://orcid.org/0000-0001-5968-330X \\ Universidade Federal de Jataí, Brasil \\ E-mail: aloisiosv@hotmail.com
}

\begin{abstract}
Resumo
O estudo anatômico de primatas não-humanos, tem exercido função importante para intervenções clínicas e cirúrgicas em atendimento da medicina veterinária. Sabe-se que o modelo experimental mais conhecido na área científica é a Macaca mulatta, popularmente conhecido como macaco Rhesus e o que a literatura tem demonstrado são novos modelos experimentais que possam suprir estudos sobre o sistema nervoso central, sendo necessário para essas descobertas um aprofundamento maior na área da anatomia comparativa. O objetivo desta revisão de literatura é promover uma visão ampla sobre os aspectos anatômicos do encéfalo de primatas humanos e não-humanos em termos comparativos. Observou-se nesta revisão algumas particularidades em primatas não-humanos referentes ao trajeto dos vasos sanguíneos no encéfalo, assim como a presença de diferentes seios venosos da dura-máter quando comparados ao primata humano. A importância do estudo morfológico no que se refere a anatomia do telencéfalo, assim como os mecanismos de revestimento, irrigação arterial encefálica e drenagem dos seios venosos da dura-máter, possibilita informações sobre a organização encefálica dos primatas não-humanos, dados esses escassos na literatura científica, mas que geram subsídios para compreensão de outras áreas de investigações etológicas e funcionais, quando comparados ao primata humano.
\end{abstract}

Palavras-chave: Encéfalo; Telencéfalo; Dura-máter; Primatas; Cérebro e círculo arterial do cérebro.

\begin{abstract}
The anatomical study of non-human primates has played an important role in clinical and surgical interventions in veterinary medicine. It is known that the most well-known experimental model in the scientific area is the Macaca mulatta, popularly known as the Rhesus monkey, and what the literature has demonstrated are new experimental models that can supply studies on the central nervous system, making it necessary for these discoveries to deepen greater in the area of comparative anatomy. The purpose of this literature review is to promote a broad view of the anatomical aspects of the brain of human and non-human primates in comparative terms. In this review, some peculiarities were observed in non-human primates regarding the path of blood vessels in the brain, as well as the presence of different venous sinuses of the dura when compared to the human primate. The importance of the morphological study regarding the anatomy of the telencephalon, as well as the mechanisms of lining, cerebral arterial irrigation and drainage of the venous sinuses of the dura mater, provides information on the brain organization of nonhuman primates, data that are scarce in the literature scientific, but that generate subsidies for understanding other areas of ethological and functional investigations, when compared to the human primate.
\end{abstract}

Keywords: Brain; Telencephalon; Dura mater; Primates; Brain and circle of Willis.

\section{Resumen}

El estudio anatómico de primates no humanos ha jugado un papel importante en las intervenciones clínicas y quirúrgicas en medicina veterinaria. Se sabe que el modelo experimental más conocido en el área científica es el Macaca mulatta, conocido popularmente como el mono Rhesus, y lo que ha demostrado la literatura son nuevos modelos experimentales que pueden aportar estudios sobre el sistema nervioso central, por lo que es necesario para 
que estos descubrimientos se profundicen más en el área de la anatomía comparada. El propósito de esta revisión de la literatura es promover una visión amplia de los aspectos anatómicos del cerebro de primates humanos y no humanos en términos comparativos. En esta revisión, se observaron algunas peculiaridades en primates no humanos con respecto al recorrido de los vasos sanguíneos en el cerebro, así como la presencia de diferentes senos venosos de la duramadre en comparación con el primate humano. La importancia del estudio morfológico respecto a la anatomía del telencéfalo, así como los mecanismos de revestimiento, irrigación arterial cerebral y drenaje de los senos venosos de la duramadre, aporta información sobre la organización cerebral de primates no humanos, datos que son escasa en la literatura científica, pero que genera subsidios para comprender otras áreas de las investigaciones etológicas y funcionales, en comparación con el primate humano.

Palabras clave: Cerebro; Telencéfalo; Duramadre; Primates; Cerebro y círculo arterial cerebral.

\section{Introdução}

A anatomia comparada tem contribuído cada vez mais para aquisição de uma grande fonte de conhecimento, principalmente por desenvolver pesquisa na área da anatomia de primatas, não apenas para a obtenção de dados acerca de sua própria constituição morfológica, mas também, como subsídios para comparação entre espécies semelhantes (Marques, 2005).

O tamanho do telencéfalo não pode ser usado como uma medida única do grau de inteligência, devido à relação complexa entre tamanho cerebral e capacidade cognitiva, como em primatas, de modo geral, os primatas são considerados mamíferos inteligentes, com telencéfalo relativamente grande (Godfrey, 2005).

Apesar da extensa quantidade de informações disponíveis sobre os primatas, ainda restam algumas lacunas de conhecimento sobre animais endêmicos ou raros, enquanto com outras espécies há uma enorme quantidade de estudos anatômicos (Nunes \& Catão-Dias, 2014). Resultado disto, foi o enfoque anatômico dado às espécies como Babuínos e Rhesus, animais estes do velho mundo (Ribeiro, 2006). Além disto, muitos estudos realizados em animais do novo mundo são provenientes do século passado (Tilney, 1928) e são de difícil acesso à comunidade científica e na rotina clínica e cirúrgica . Exemplo disso, foram os estudos realizados por Marques (2005) e Ribeiro (2006), que descreveram a anatomia do tronco encefálico, hipófise e cerebelo, respectivamente, do macaco prego (Sapajus libidinosus), assim como, a espécie Guariba ou Bugio (Alouatta belzebul) que teve descrito por vários autores em estudos anatômicos, a medula espinal (Souza-Terra et al., 2018), a vascularização do encéfalo (Sabec-Pereira et al., 2020a), o tubo digestório (Segantine et al., 2020), os seios venosos da dura-máter (Sabec-Pereira et al., 2020b), o sistema reprodutor feminino (Pereira et al., 2020) e o sistema respiratório (Fernandes et al., 2020), dados que contribuíram para descrição morfológica desta espécie de primata e assim possibilitando melhoria na atuação clínica e cirúrgica veterinária, além de fornecer dados para anatomia comparada das diferentes espécies e os aspectos evolutivos dos mesmos.

A morfologia insere-se nesse contexto, uma vez que é a ciência que estuda a diversidade das formas que os seres vivos podem assumir, sendo esta, a ferramenta básica utilizada amplamente pelas ciências biológicas. Os estudos anatômicos em diferentes espécies proporcionam informações que se somam e passam a constituir importante fonte de consulta para a sociedade e comunidade científica. Assim, entende-se que os conhecimentos dos diversos aspectos da neuroanatomia de primatas não-humanos, escassos ainda, são importantes não apenas pelo seu valor intrínseco, mas o de oferecer subsídios para um melhor entendimento do processo evolutivo destes animais, o que representa fator relevante para sua preservação e proteção (Aversi-Ferreira et al.,2005).

A demanda por primatas não-humanos para servirem como modelos na pesquisa científica tornam esses animais a cada dia mais importantes. Estudos comparativos são essenciais para o desenvolvimento das ciências biológicas, em especial para a neurociência, devido principalmente pela dificuldade de procedimentos experimentais invasivos em humanos. Deste modo, as análises encefálicas, em especial de primatas não-humanos, são de fundamental importância para a compreensão dos diversos elementos neurais assim como seus aspectos anatômicos e fisiológicos, além de proverem inferências acerca da evolução da cognição em primatas (Marques et al., 2005; Pereira-de-Paula et al., 2010; Pissinatti et al., 2010). 
Neste contexto, a obtenção de dados sobre os aspectos morfológicos do telencéfalo e, consequentemente, das regiões corticais, da vascularização encefálica e da drenagem venosa de primatas não-humanos, podem vir a ser um modelo para interpretações neurofisiológicas, além de propiciar dados para as correlações filogenéticas e evolutivas com outros primatas (Bush \& Allman, 2004). O objetivo desta revisão é elencar considerações gerais sobre o encéfalo de primatas humanos e nãohumanos em caráter comparativo para que possa vir a subsidiar pesquisas clínicas relacionadas com a neuroanatomia.

\section{Metodologia}

Trata-se de uma revisão narrativa da literatura (Pereira et al., 2018) de caráter qualitativo no qual foram consultadas as bases de dados da Biblioteca Virtual em Saúde (BVS), Scielo, PubMed, Periódico CAPES, Scopus e livros, tendo sido pesquisados artigos até 2020, nos idiomas inglês e português. As palavras-chave "encéfalo, primatas, cérebro, círculo arterial do cérebro, dura-máter, monkey, brain", foram combinadas entre si como estratégia de busca em cada base de dados. Foram utilizados artigos que abordassem assuntos pertinentes ao objetivo deste estudo, além de livros que abordam a anatomia descritiva do encéfalo de primatas humanos e não-humanos. Foram excluídos artigos provenientes de estudos experimentais clínicos comportamentais em outros animais. As informações levantadas dos artigos selecionados foram organizadas para informar sobre a morfologia e a fisiologia do encéfalo de primatas humanos e não-humanos. Foram utilizadas 62 fontes para a elaboração desta revisão.

\section{Resultados e Discussão}

Os primatas são pertencentes à classe Mammalia e ocorrem em ambientes tropicais e subtropicais ao longo de todo o mundo, exceto na Austrália (Kassell \& Langfitt, 1965). Contém ao todo 16 famílias, 77 gêneros, 488 espécies e 690 subespécies que estão divididas em duas subordens: Prosimii e Antropoidea. A subordem Antropoidea ainda subdivide-se em dois grandes grupos: os Platyrrhini - grupo de primatas do Novo Mundo (PNM) e os Catarrhini - grupo de primatas do Velho Mundo (PVM). Os PNM estão distribuídos na América Central e do Sul e apresentam uma grande diversidade em padrões de coloração, localização e tamanho das espécies. Por outro lado, os PVM são de ocorrência dos continentes asiático e africano (Nunes \& Catão-Dias, 2014; Guimarães, 2007; Rylands, 2014; Lynch et al., 2014; Silva et al., 2017).

Os PNM distinguem-se dos PVM por possuírem septo nasal largo e cavidades nasais voltadas para os lados, focinho curto, polegar não completamente oponível, ausência de tuberosidade isquiática e de bolsas jugais, dentição constituída por 32 ou 36 dentes, sendo três pré-molares com três ou quatro protuberâncias na mandíbula inferior e superior (Bicca-Marques et al., 2011). A ordem dos Primatas é considerada a primeira na escala zoológica por ser a mais evoluída do reino animal e dividida em duas subordens: Prosimii e Anthropoidea. A primeira inclui os prossímios (evolutivamente mais primitivos) e a segunda divide-se em dois grandes grupos: a infra ordem Catarrhini e a Plathirrini. Ao todo essa ordem possui 13 famílias (Kindlovits \& Kindlovits, 2009).

Praticamente todos os primatas não-humanos se encontram em áreas tropicais ou subtropicais, próximos à linha equatorial. O fato é que, ao longo da história da evolução das espécies, os primatas afro-asiáticos e os neotropicais seguiram caminhos diferentes, o que se expressa em diferentes características morfológicas, das quais talvez a mais típica seja a diferença na conformação das narinas. Muitos outros caracteres, como a cauda preênsil nos platirrinos e a calosidade isquiática nos catarrinos distinguem morfologicamente esses dois grandes grupos de primatas. Dentre os mais conhecidos representantes dos primatas afro-asiáticos (ou do velho mundo), podemos citar os Gibões (Hylobates sp.), Orangotango (Pongo pygmaeus), Chimpanzé (Pan troglodytes), Gorila (Gorilla gorilla), Mandril (Mandrillus sphinxs), Babuíno (Papio cynocephalus) e o macaco Rhesus (Macaca mulatta). Entre os primatas neotropicais (ou do novo mundo) pode-se destacar o Macaco-Prego (Sapajus libidinosus), o Macaco Aranha (Ateles sp), o Macaco Barrigudo (Lagothrix sp), Bugio (Alouatta sp), Muriqui 
(Brachyteles arachnoides) e o Sagui (Callithrix sp) (Diniz, 1997).

O Brasil é considerado o detentor da maior diversidade de primatas não-humanos do mundo. Somente na Mata Atlântica ocorrem 24 espécies, sendo 17 endêmicas o que confirma que a diversidade biológica do Brasil ainda é pouco conhecida, apesar de ser considerada a maior do planeta, e o estado de conhecimento sobre os mamíferos do Brasil segue essa mesma tendência (Santana et al., 2008).

Em humanos, o encéfalo é dividido em dois hemisférios que são incompletamente separados pela fissura longitudinal do telencéfalo e unidos por feixes de fibras que formam as comissuras. Cada hemisfério é composto por regiões anatômicas denominadas giros, que são dobras do tecido cerebral em formato de pregas delimitadas por sulcos (Figuras 3 e 4), depressões de profundidade diferenciadas. Essas regiões são compostas por substância cinzenta (córtex cerebral) e substância branca subjacente (Martinez et al., 2014).

Os hemisférios cerebrais no desenvolvimento embrionário surgem no início da quinta semana como evaginações bilaterais da parede lateral do prosencéfalo. Durante a quinta semana do desenvolvimento embrionário, o encéfalo anterior (prosencéfalo) se divide parcialmente em duas vesículas encefálicas secundárias: o telencéfalo e o diencéfalo. A parte rostral, ou anterior constitui o telencéfalo, enquanto a parte caudal, ou posterior, do encéfalo anterior constitui o diencéfalo. As cavidades do telencéfalo e do diencéfalo contribuem para a formação do terceiro ventrículo. Até a metade do segundo mês, a porção basal dos hemisférios começa a crescer e se projetar para o lúmen do ventrículo lateral e para o assoalho do forame magno (Moore \& Persaud, 2008).

Em cortes transversais, a região embrionária que cresce rapidamente tem aparência estriada e é conhecida, por corpo estriado. Na região em que a parede do hemisfério está ligada ao teto do diencéfalo, esta não consegue desenvolver neuroblastos e permanece muito fina. Neste local, o hemisfério consiste em uma única camada de células ependimárias recobertas por mesênquima vascularizado, o qual compõem o plexo coroide. O crescimento contínuo dos hemisférios cerebrais nos sentidos anterior, dorsal e inferior, resulta na formação dos lobos frontal, temporal e occipital, respectivamente. No entanto, à medida que diminui o crescimento da região sobrejacente ao corpo estriado, a área entre os lobos frontal e temporal formam uma depressão conhecida como ínsula. Essa região, durante o desenvolvimento é coberta pelos lobos adjacentes e, ao nascimento, está quase completamente coberta. No final do desenvolvimento fetal, a superfície dos hemisférios cerebrais cresce rapidamente e aparecem muitas circunvoluções (giros) separados por fissuras e sulcos (Sadler, 2019).

O encéfalo humano recebe outra classificação que delimita as regiões encefálicas, os chamados lobos. Existem cinco lobos cerebrais: lobo frontal, lobo parietal, lobo temporal, lobo occipital (Figuras 1 e 2) e lobo da ínsula (Figura 3), que em humanos acompanham os ossos do crânio (Afifi \& Bergman, 2008). 
Figura 1. Vista lateral esquerda do hemisfério cerebral de Homo, no qual é possível identificar os sulcos, os giros e os principais lobos cerebrais.

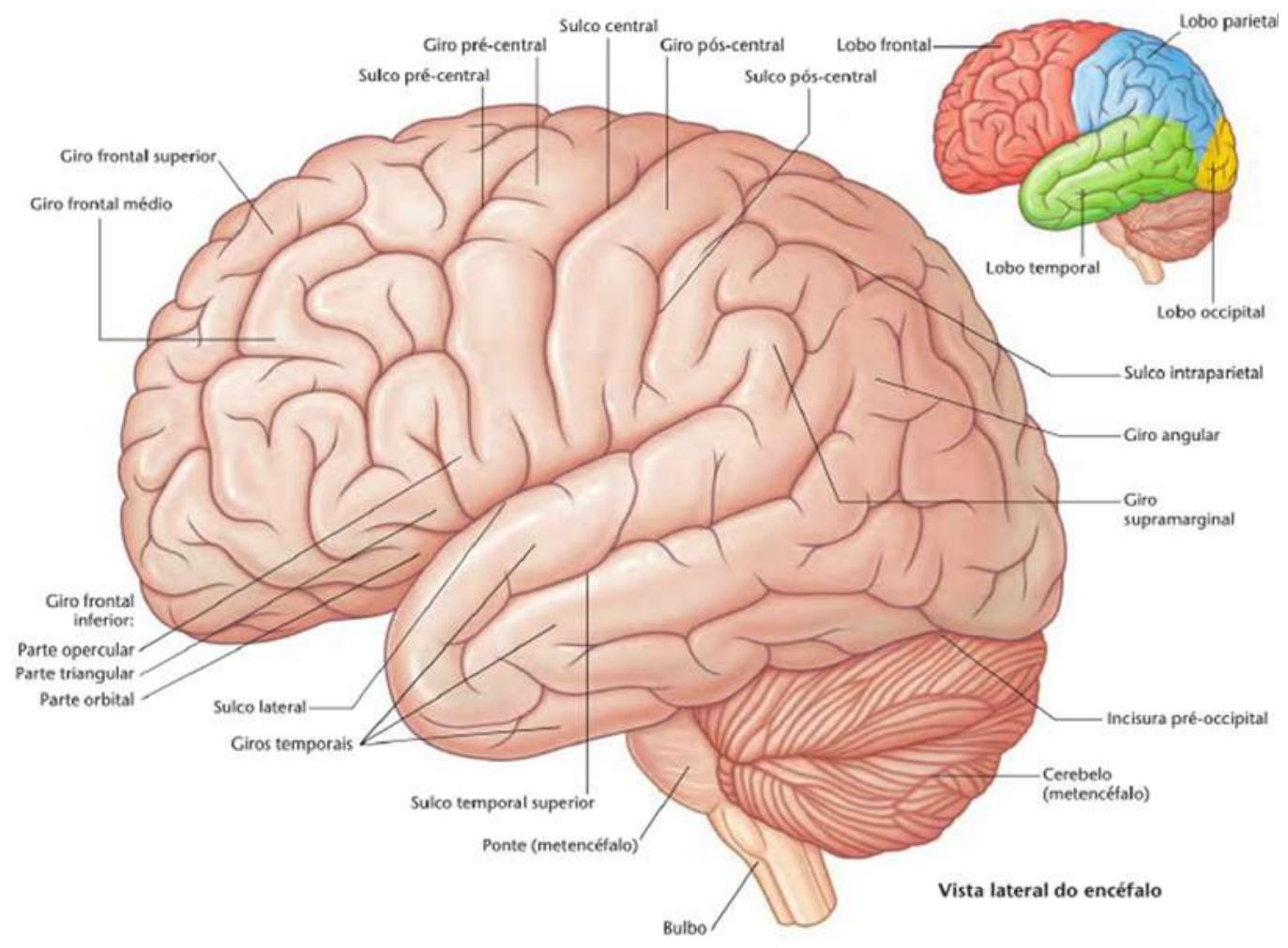

Fonte: Drake et al. (2011).

Figura 2. Vista medial direita do hemisfério cerebral de Homo, ao qual é possível identificar sulcos e giros do telencéfalo e estruturas diencefálicas.

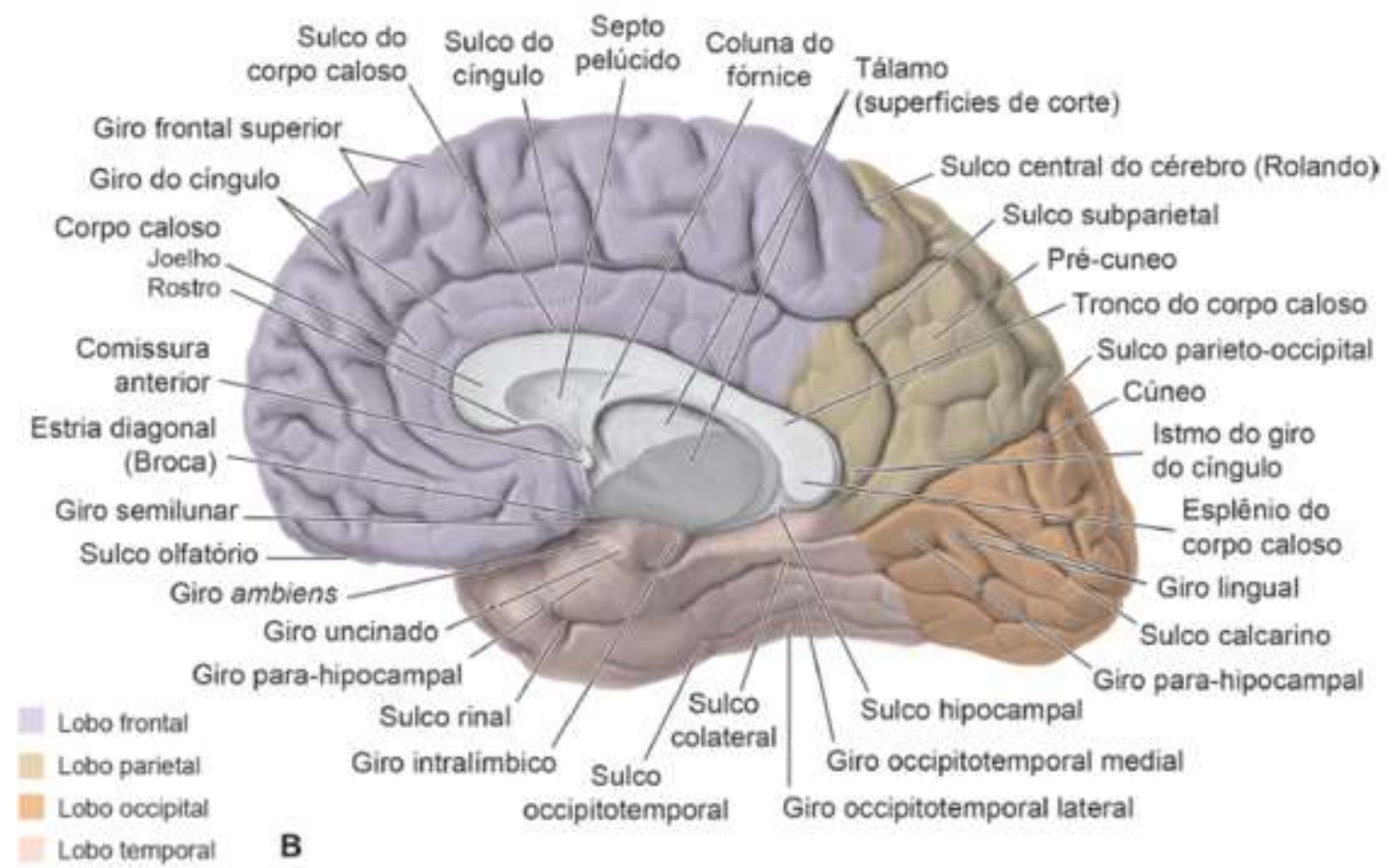

Fonte: Martinez et al. (2014). 
O lobo frontal localiza-se no polo anterior do hemisfério é separado pelo sulco central do lobo parietal e pelo sulco lateral do lobo temporal. O lobo parietal está localizado laterodorsalmente no hemisfério sendo desagregado do lobo occipital pelo sulco parieto-occipital. Além destes quatro lobos, o lobo da ínsula (Figura 5) localiza-se profundamente ao hemisfério, visível apenas quando é realizada a dissecação do lobo temporal e parte do frontal (Brandão, 2004; Meneses, 2011).

Figura 3. Vista lateral do hemisfério esquerdo de Homo, em que parte do lobo temporal e do lobo frontal foram rebatidas para visualização do lobo da ínsula (círculo) com características girencefálicas.

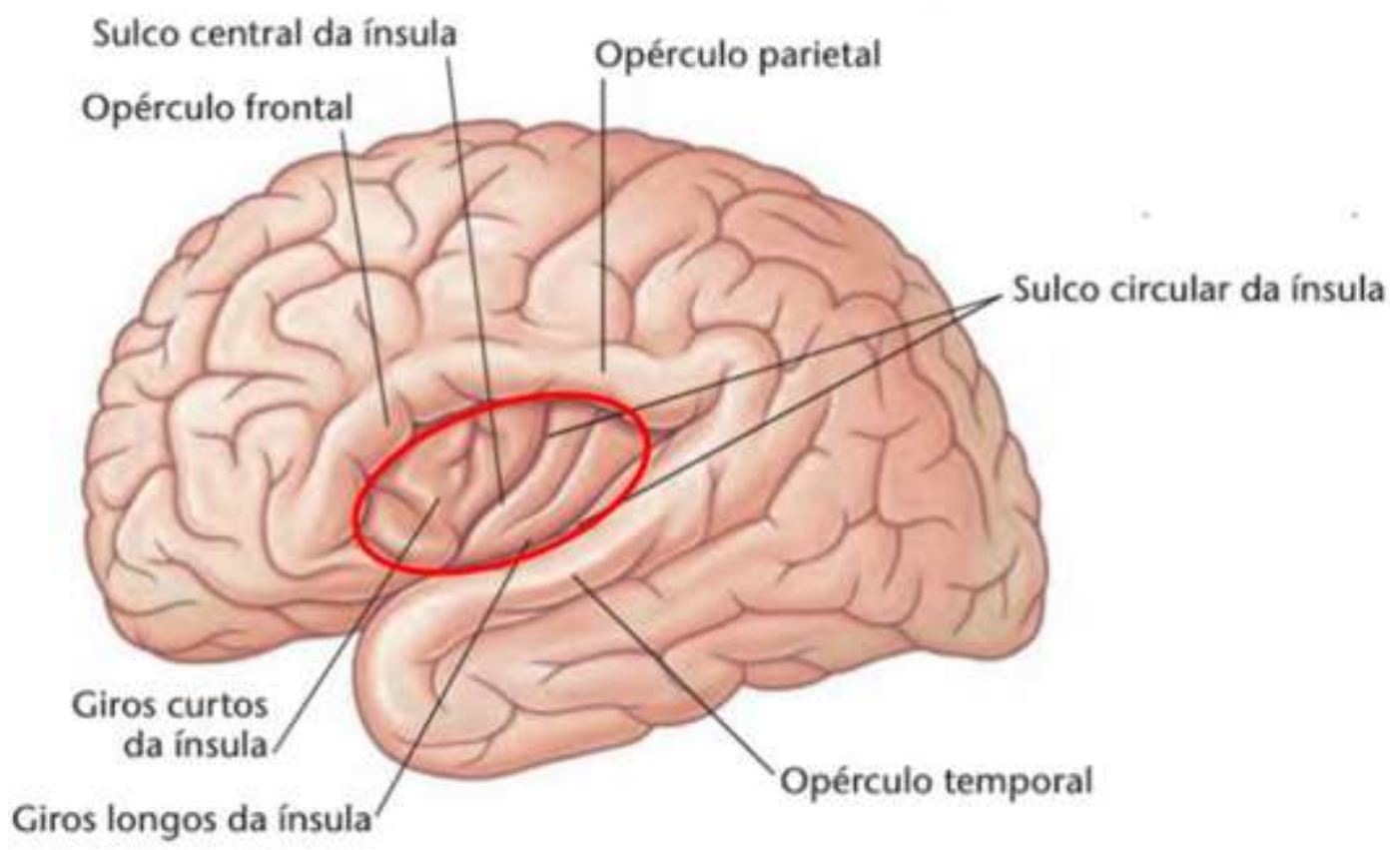

Fonte: Adaptado de Drake et al., (2011).

O lobo frontal é dividido por alguns sulcos importantes, sendo: o sulco pré-central está posicionado anteriormente ao sulco central, o sulco frontal superior situado perpendicularmente na porção superior do sulco pré-central e sulco frontal inferior que se localiza perpendicularmente na porção inferior do sulco pré-central. Entre o sulco central e pré-central a região margeada é denominada giro pré-central, no qual se localiza a área motora primária (M1). Os sulcos do lobo frontal vão delimitar o giro frontal superior, o giro frontal médio e o giro frontal inferior. Nessa região encontram-se a área pré-motora (superiormente) e a área motora suplementar (mais inferiormente, paralela ao sulco) que são fortemente conectadas entre si e à área motora primária. Essas duas áreas estão funcionalmente relacionadas com o planejamento motor, enquanto M1 está relacionada com a execução das ações motoras (Martin, 2014).

O giro frontal inferior é dividido em ramos anterior e ascendente do sulco lateral em três partes: orbital (região do giro frontal inferior abaixo do ramo anterior), triangular (região do giro frontal inferior entre o ramo anterior e o ramo ascendente) e opercular (região do giro frontal inferior entre o ramo ascendente e o sulco pré-central). O giro frontal inferior do hemisfério esquerdo é denominado giro ou área de Broca, descoberta pelo neurologista francês Pierre Paul Broca (1824-1880), que correlacionou a afasia motora em um de seus pacientes com a lesão focal dessa porção cortical. Nessa região, localiza-se, portanto, na maioria dos indivíduos, a área motora da fala (Machado, 2013).

O lobo temporal apresenta sulcos e giros visíveis na face lateral e na face inferior do hemisfério. Os principais sulcos do lobo temporal na face lateral são o sulco temporal superior e sulco temporal inferior que seguem paralelos ao sulco lateral, no entanto apresentam descontinuidades. Esses dois sulcos, delimitam três giros, giro temporal superior, giro temporal médio e 
giro temporal inferior. Removendo parte dos lobos frontal e parietal é possível visualizar o giro temporal superior e identificar três giros temporais transversos que compõem a área auditiva primária. Nesse local observam-se também os sulcos e giros do lobo da ínsula (de anterior para posterior): giros curtos da ínsula, sulco central da ínsula, sulco circular da ínsula e giro longo da ínsula, responsáveis pelo sistema límbico (Carneiro, 2004).

O lobo parietal apresenta o sulco pós-central, paralelo ao sulco central, porém descontínuo e frequentemente fundido com o sulco intraparietal, horizontalizado e direcionado posteriormente. Entre o sulco central e o pós-central, está o giro póscentral, que abriga a região funcional somestésica primária (S1). Inferiormente ao sulco intraparietal, observa-se mais anteriormente o giro supramarginal, que se curva sobre a extremidade do ramo posterior do sulco lateral e mais posteriormente, o giro angular, que se curva sobre a extremidade do sulco temporal superior (Martinez et al., 2014).

A face inferior é representada apenas pelos lobos frontal e temporal. O lobo temporal apresenta três sulcos longitudinais importantes: sulco occipitotemporal, sulco colateral e sulco do hipocampo. Entre o sulco occipitotemporal e o sulco temporal inferior, encontra-se o giro temporal inferior, que forma a borda lateral do hemisfério. Entre o sulco occipitotemporal e o sulco colateral, nota-se o giro occipitotemporal lateral ou giro fusiforme. Entre o sulco colateral e o sulco calcarino encontra-se o giro occipitotemporal medial. O sulco colateral continua-se anteriormente com o sulco rinal, e entre eles e o sulco do hipocampo encontra-se o giro para-hipocampal. A porção anterior do giro para-hipocampal contorna o sulco do hipocampo e passa, então, a ser denominada úncus. O sulco do hipocampo prolonga-se na região do esplênio do corpo caloso com o sulco do corpo caloso, na face medial do hemisfério (Brandão, 2004; Meneses, 2011) (Figura 4).

Figura 4. Vista ventral do encéfalo de Homo, evidenciando os principais sulcos e giros localizados inferiormente nos hemisférios cerebrais.

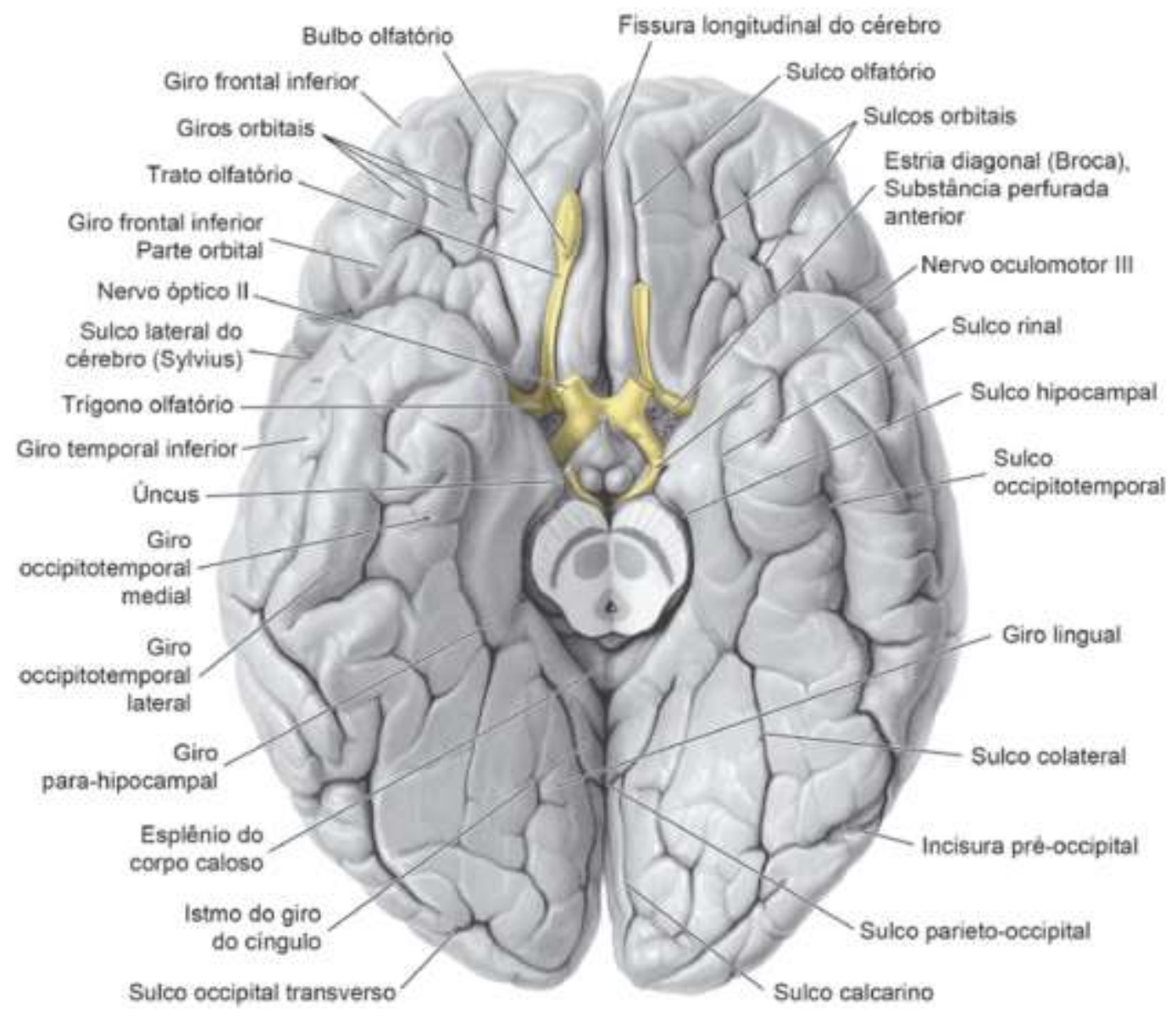

Fonte: Meneses (2011). 
O diencéfalo humano é composto por estruturas importantes, entre elas o tálamo, hipotálamo, epitálamo, metatálamo e subtálamo. As estruturas límbicas também se localizam nesta região do telencéfalo, hipocampo, amígdala e fórnice, comissura habenular, comissura posterior e comissura anterior (Meneses, 2011; Machado, 2013).

O tálamo está situado no diencéfalo, acima do sulco hipotalâmico, e faz parte do sistema límbico. É fundamentalmente constituído de substância cinzenta, na qual se distinguem vários núcleos. Apresentam duas grandes massas ovóides de tecido nervoso, com uma extremidade anterior pontuda, o tubérculo anterior do tálamo, e outra posterior, bastante proeminente, o pulvinar do tálamo. Os dois ovóides talâmicos estão unidos pela aderência intertalâmica e relacionam-se medialmente com o III ventrículo, a porção posterior apresenta uma grande eminência, que se projeta sobre os corpos geniculados lateral e medial. O corpo geniculado medial faz parte da via auditiva; o lateral da via óptica (Martinez et al., 2014; Martin, 2014).

O hipotálamo é uma pequena porção do diencéfalo, localizado abaixo do tálamo, e relacionado principalmente com as funções viscerais. O hipotálamo compreende as estruturas situadas nas paredes laterais do III ventrículo, além das seguintes estruturas que fazem parte do assoalho do III ventrículo: corpos mamilares, arredondados e evidentes na arte anterior da fossa interpeduncular; quiasma óptico, parte anterior do assoalho recebe as fibras mielínicas dos nervos ópticos; túber cinéreo, situada atrás do quiasma óptico, entre estes e os corpos mamilares; infundíbulo, que liga o hipotálamo a hipófise (Machado, 2013; Kiernan, 2014).

O epitálamo limita posteriormente o III ventrículo onde encontra-se a glândula pineal, glândula endócrina piriforme ímpar que repousa sobre o tecto mesencefálico. Os trígonos da habênula, situados entre a pineal e o tálamo, está interposta entre as comissuras da habênulas. O subtálamo compreende a zona de transição entre o diencéfalo e o tegmento mesencefálico (Van de Graaff, 2003; Kiernan, 2014).

Em relação aos estudos realizados com primatas não-humanos, observa-se características diferentes em relação a anatomia do córtex encefálico, como por exemplo, em Sapajus libidinosus (Pereira-de-Paula et al., 2010), o lobo occipital, lobo frontal e o lobo da ínsula apresentam características lisoencefálicas, o que difere de Homo (Machado, 2013) e o lobo parietal e temporal apresentam lobos totalmente girencefálicos, dados que corroboram com Alouatta seniculus (Tilney, 1928) e Homo (Machado, 2013). O lobo parietal e temporal de Sapajus libidinosus foram similares aos babuínos, com giros e sulcos bem definidos e delimitados, apenas o sulco central apresentou-se pouco menos inclinado e sinuoso quando comparado com babuínos, humanos e chimpanzés (Pereira-de-Paula et al., 2010), conforme demonstrado na Figura 5. 
Figura 5. Vista anterolateral do telencéfalo de Sapajus libidinosus mostrando os principais sulcos.

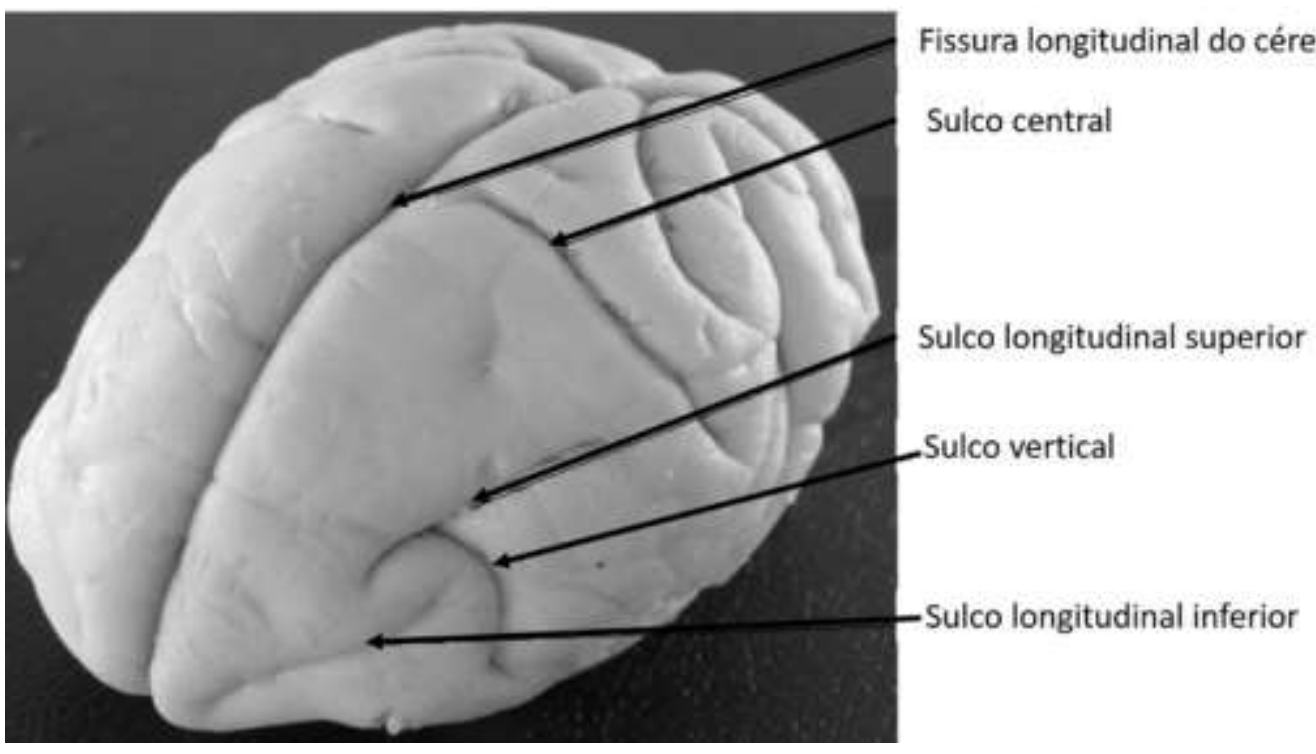

Fonte: Pereira-de-Paula et al. (2010).

A face convexa lisoencefálica no lobo occipital e ínsula e os poucos sulcos e giros do lobo frontal em Sapajus libidinosus, não tem semelhança com Papio, Pan e Homo, de acordo com as descrições de Swindler \& Wood (1973). No entanto, as faces convexas dos lobos parietais e temporais são semelhantes às descrições para babuíno.

Em estudo realizado com o telencéfalo de macaco aranha (Ateles $s p$ ) por meio de ressonância magnética, verificou-se estruturas semelhantes aos humanos como: o sulco lateral, sulco central, sulco parieto-occipital, sulco calcarino e sulco do cíngulo. A curvatura cervical, amígdala, hipocampo, comissura anterior e colículo, eram maiores no macaco-aranha do que no homem. Os autores discutem que a comissura anterior é mais espessa nos primatas não-humanos, entretanto a sua função em relação a essa diferença morfológica não está descrita na literatura (Chico-Ponce et al., 2009).

Em dezenove espécimes de Macaca fascicularis, observou-se a organização anatômica do córtex pré-frontal lateral em relação às conexões aferentes do lobo temporal anterior. Considerando que o lobo temporal anterior é composto por diferentes áreas corticais, os pesquisadores associaram a anatomia macroscópica com a atividade funcional das áreas corticais, sugerindo que a atividade funcional do lobo frontal é transmitida para o lobo temporal lateral através das suas subdivisões dorsal e ventral, deixando evidente que o córtex pré-frontal lateral dorsal é responsável pela maior parte das conexões com o lobo temporal anterior, enquanto o córtex pré-frontal lateral ventral realiza pouca conexões. Indiretamente, estas conexões intrínsecas do lobo frontal podem acessar o córtex entorrinal e promover a formação do hipocampo neste primata (MohedanoMoriano et al., 2015).

O desenvolvimento do corpo caloso em humanos comparado com chimpanzés foi estudado por Sakai et al., (2017), observaram em humanos que o corpo caloso se expande rapidamente durante a infância, seguido de mudanças relativamente lentas. Nos chimpanzés, as mudanças são rápidas durante o estágio inicial de desenvolvimento e mais tarde ficam lentas e estabilizam. O rostro do corpo caloso é conhecido por transportar fibras entre o córtex pré-frontal e pré-motor bilateral, responsável pelo controle do comportamento, na memória de trabalho e no controle da atenção, o que diferenciaria um adulto humano de um adulto não-humano (chimpanzé) do ponto de vista comportamental. Este estudo é de suma importância para o entendimento da anatomia do corpo caloso, que em primatas humanos e não-humanos é semelhante até o final da infância, em termos de aumento do volume, elaboração sináptica, mielinização e estabelecimento de conexões padrões (Sakai et al., 2017).

Estudos realizados por Broca (2015) sobre anatomia comparativa das circunvoluções do telencéfalo envolvendo o 
lobo da ínsula na classe Mammalia, descrevem numerosas modificações durante a evolução. O ponto de partida está relacionado com a predominância do lobo frontal revestindo os giros parietais, influenciando na formação dos lobos occipitais e temporais e, consequentemente, no aumento do lobo frontal, dificultando a formação do lobo insular dentro do sulco lateral. Os autores analisaram ainda as mudanças do lobo insular atrofiando os sistemas visíveis em cetáceos e anfíbios. Afirmam que todos os tipos de telencéfalo diferem uns dos outros apenas em características evolutivas, isto é, em forma e tamanho relativo, e não na natureza de suas partes componentes (Broca, 2015).

As evoluções do córtex parietal posterior em primatas levaram a várias conclusões sobre esta região. Nos primeiros mamíferos, o córtex parietal posterior foi determinado como uma pequena região multissensorial e nos primeiros primatas apresenta a porção caudal, a visual e a rostral, com função de oito ou mais domínios multissensoriais, onde a estimulação elétrica evoca diferentes comportamentos motores complexos, incluindo o alcance da mão na boca, observar e proteger seu rosto e corpo e segurar objetos. Os domínios em cada região competem uns com os outros e uma disposição serial de domínios permite que diferentes fatores influenciem os resultados motores sucessivamente. Arranjos similares de domínios foram mantidos em macacos do Novo e do Velho Mundo, e os humanos parecem ter pelo menos alguns desses domínios. A grande expansão e o desenvolvimento prolongado de córtex parietal posterior em seres humanos sugerem a adição de territórios funcionalmente distintos (Kaas \& Stepniewska, 2016).

Diferente de outros grupos de animais, os primatas são caracterizados por um tamanho aumentado do telencéfalo, pela melhoria das habilidades cognitivas e manipuladoras e pelo aumento do comportamento social complexo quando estão em grupo. Esses traços influenciam a forma como os indivíduos codificam e usam informações na tomada de decisões e desenvolvem-se principalmente com a combinação de mudanças no sistema visual e expansão do córtex cerebral (Lewitus et al., 2016).

\subsection{Anatomia macroscópica das meninges encefálicas em primatas não-humanos e humanos.}

O encéfalo, assim como a medula espinal encontram-se envolvidos por três membranas ou meninges, que são denominadas paquimeninge (dura-máter) e leptomeninge (pia-máter e aracnoide-máter) (Warwick et al., 1980) (Figura 8).

A meninge dura-máter é a mais externa, está localizada sob o periósteo responsável por revestir a superfície interna do canal vertebral, com características morfológicas apresentando espessura e resistência por ser composta de fibras colágenas e elásticas, além de ser muito vascularizada e inervada (Martinez et al., 2014; Sakka \& Chazal, 2005; Weller, 2005).

A meninge aracnoide-máter é considerada intermediária, pois está entre a dura-máter e a pia-máter, apresenta uma membrana delgada e muito delicada, como se fosse uma teia de aranha, não possui vascularização nem nervos (Carneiro, 2004). Esta delimita externamente o espaço subaracnóideo, onde encontramos liquor. Como a pia-máter acompanha o tecido nervoso, inclusive onde existem depressões, há a formação de espaços denominadas cisternas, que contêm maior quantidade de liquor (Meneses, 2011).

O liquor produzido nas cavidades ventriculares em Homo, passa para o espaço subaracnóideo pela abertura mediana e pelas aberturas laterais do quarto ventrículo em direção à cisterna magna. Dessa cisterna, o liquor circula em volta da medula espinal e do encéfalo até ser absorvido no nível das granulações aracnoides existentes nos seios da dura-máter, passando à circulação sanguínea. Aproximadamente $75 \mathrm{ml}$ de liquor circulam no espaço subaracnóideo do canal vertebral, e $25 \mathrm{ml}$, na região intracraniana (Martinez et al., 2014).

Em alguns pontos, os feixes de tecido que compõem a aracnoide-máter formam enovelados, recebendo o nome de granulações aracnóideas, que penetram nos seios da dura-máter, principalmente no seio sagital superior. Nas granulações aracnóideas o liquor é reabsorvido e direcionado à circulação venosa (Martin, 2014).

A meninge pia-máter é a mais interna. Constituída de tecido reticular e fibras colágenas, penetra entre os giros dos 
hemisférios cerebrais e entre as folhas do cerebelo e é ricamente vascularizada e inervada (Afifi \& Bergman, 2008).

Figura 6. Vista súpero-lateral do encéfalo de Homo, evidenciando as meninges dura-máter, aracnoide-máter e pia-máter.

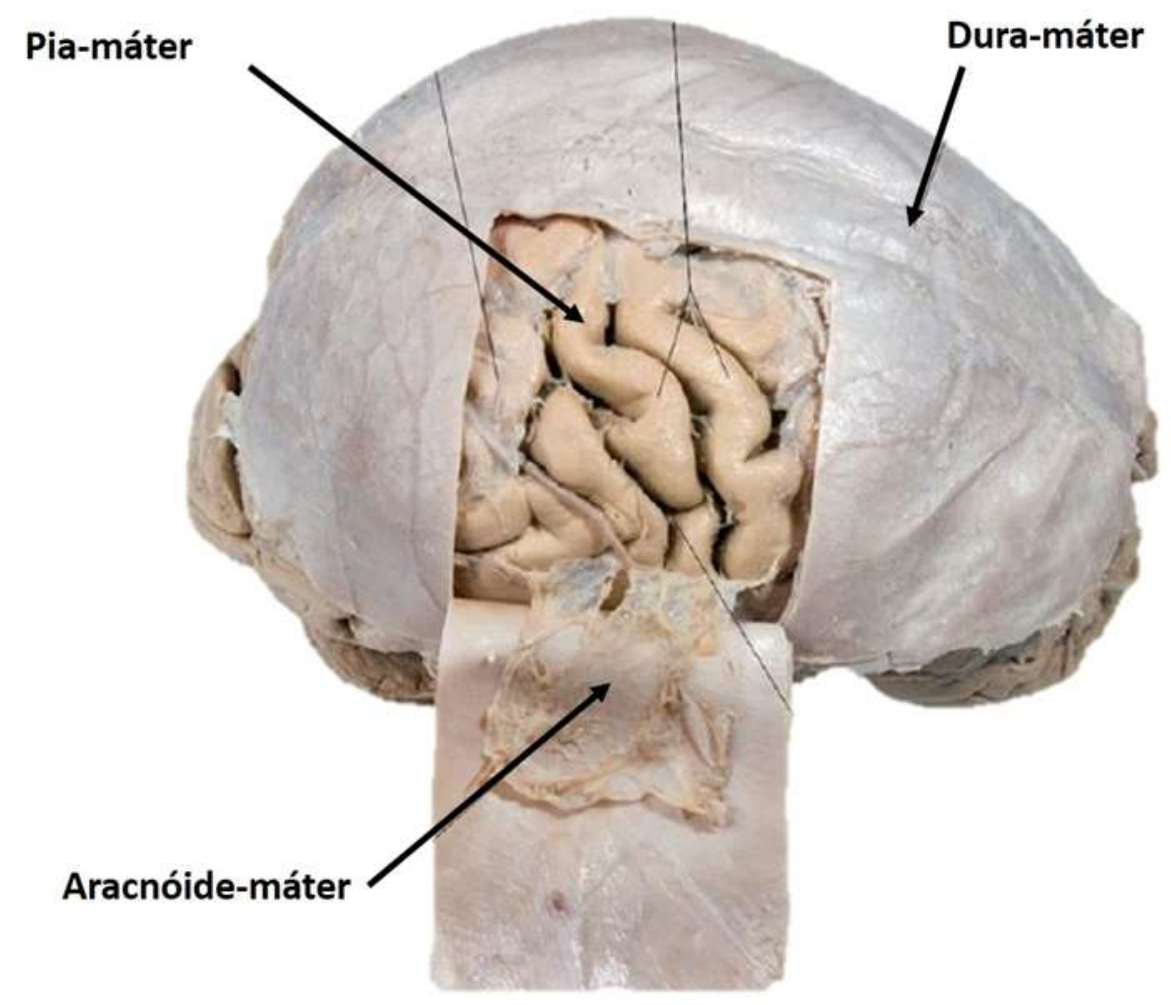

Fonte: Colicigno et al. (2009).

A principal função das meninges é revestir o sistema nervoso central (SNC), garantindo a proteção contra choques mecânicos e a regulação da pressão no interior desse importante sistema (Warwick et al., 1980).

Assim, na região encefálica, não há formação de um espaço epidural entre os ossos e a dura-máter, conforme se observa em nível medular (Martin, 2014). Grande parte da capacidade regenerativa para a consolidação de fraturas dos ossos do crânio se dá pela capacidade osteogênica da dura-máter. Seu potencial regenerativo evidencia-se até os 2 anos de idade, declinando após esse período, devido à sub-regulação da expressão de fatores osteogênicos. $\mathrm{O}$ folheto interno acompanha o externo em todo o entorno do encéfalo, mas se destaca daquele em determinadas áreas, formando pregas e cavidades (seios) (Carneiro,2004). As pregas dividem incompletamente a cavidade craniana (Figura 7). São elas:

- Foice do telencéfalo: é um septo vertical que separa os dois hemisférios e se localiza na fissura longitudinal do telencéfalo.

- Tenda do cerebelo: é um septo transversal localizado entre os lobos occipitais e o cerebelo, dividindo a cavidade craniana em uma fossa superior (supratentorial) e outro inferior (infratentorial), e terminando na incisura da tenda, uma borda livre que se ajusta ao mesencéfalo.

- Foice do cerebelo: é um septo vertical que separa incompletamente os dois hemisférios cerebelares.

- Diafragma da sela: é uma pequena lâmina horizontal que fecha incompletamente a sela túrcica, deixando um orifício de passagem para a haste hipofisária. 
Figura 7. Vista inferior da dura-máter de Homo isolada com a técnica de plastinação, evidenciando a foice do telencéfalo e cerebelo medialmente e a tenda do cerebelo posteriormente.

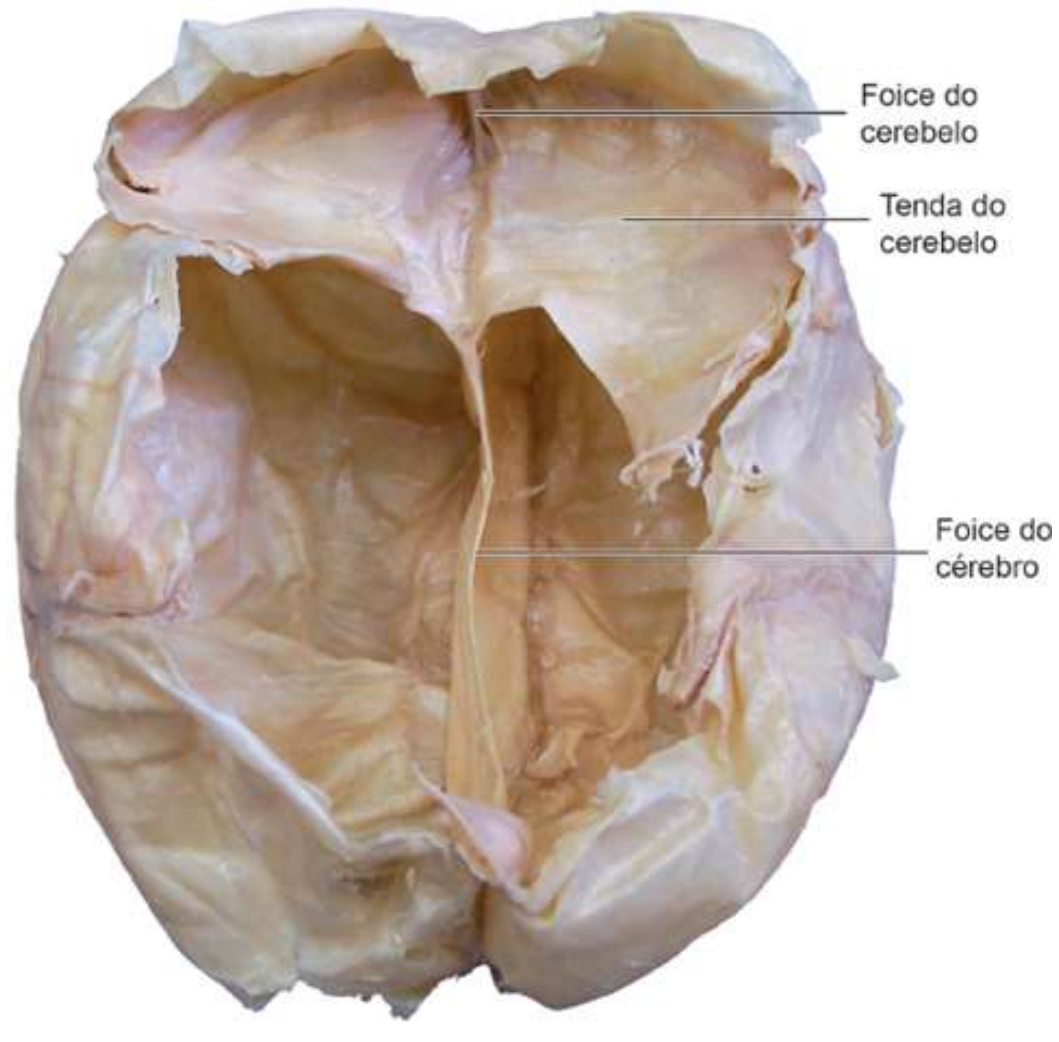

Fonte: Snell (2003).

As cavidades formadas pela dura-máter são, em sua maioria, revestidas de endotélio e contêm sangue, formando seios venosos. Estes seios apresentam forma triangular e são dispostos, principalmente, ao longo das pregas da dura-máter. Recebem o sangue proveniente das veias do encéfalo e do globo ocular e drenam para as veias jugulares internas. Os seios comunicamse com veias da superfície externa pelas veias emissárias que atravessam forames nos ossos cranianos (Martin, 2014). Têm as seguintes divisões (Figura 8):

- Seio sagital superior: mediano, acompanha a inserção da foice do telencéfalo, seguindo caudal e posteriormente para desaguar na confluência dos seios.

- Seio occipital: situa-se ao longo da margem de inserção da foice do cerebelo

- Seio sagital inferior: corre paralelamente ao sagital superior, porém na margem livre da foice do telencéfalo, desaguando no seio reto.

- Seio reto: localiza-se no ponto de união entre a foice do telencéfalo e a tenda do cerebelo; termina na confluência dos seios.

- Seios transversos direito e esquerdo: dispõem-se ao longo da inserção da tenda do cerebelo desde a confluência dos seios até a parte petrosa do osso temporal, na qual passa a ser designado seio sigmoide.

- Seio sigmoide: continuação do seio transverso até o forame jugular, de onde prossegue a veia jugular interna. Pela jugular é drenada quase a totalidade do sangue da cavidade craniana.

- Seio cavernoso: seio da base do crânio situado de cada lado do corpo do osso esfenoide e da sela túrcica.

Comunica-se com o seio cavernoso do lado oposto por meio do seio inter-cavernoso. É atravessada pela artéria carótida interna.

- Seios petrosos superior e inferior: O seio petroso superior, apresenta um trajeto sobre a porção petrosa do 
osso temporal. O seio petroso inferior faz a anastomose do seio carvernoso com o bulbo da veia jugular interna no nível do seu forame, passando por um sulco lateralmente ao clivo.

Figura 8. Vista lateral do hemicrânio esquerdo de Homo, evidenciando os seios da dura-máter e suas veias.

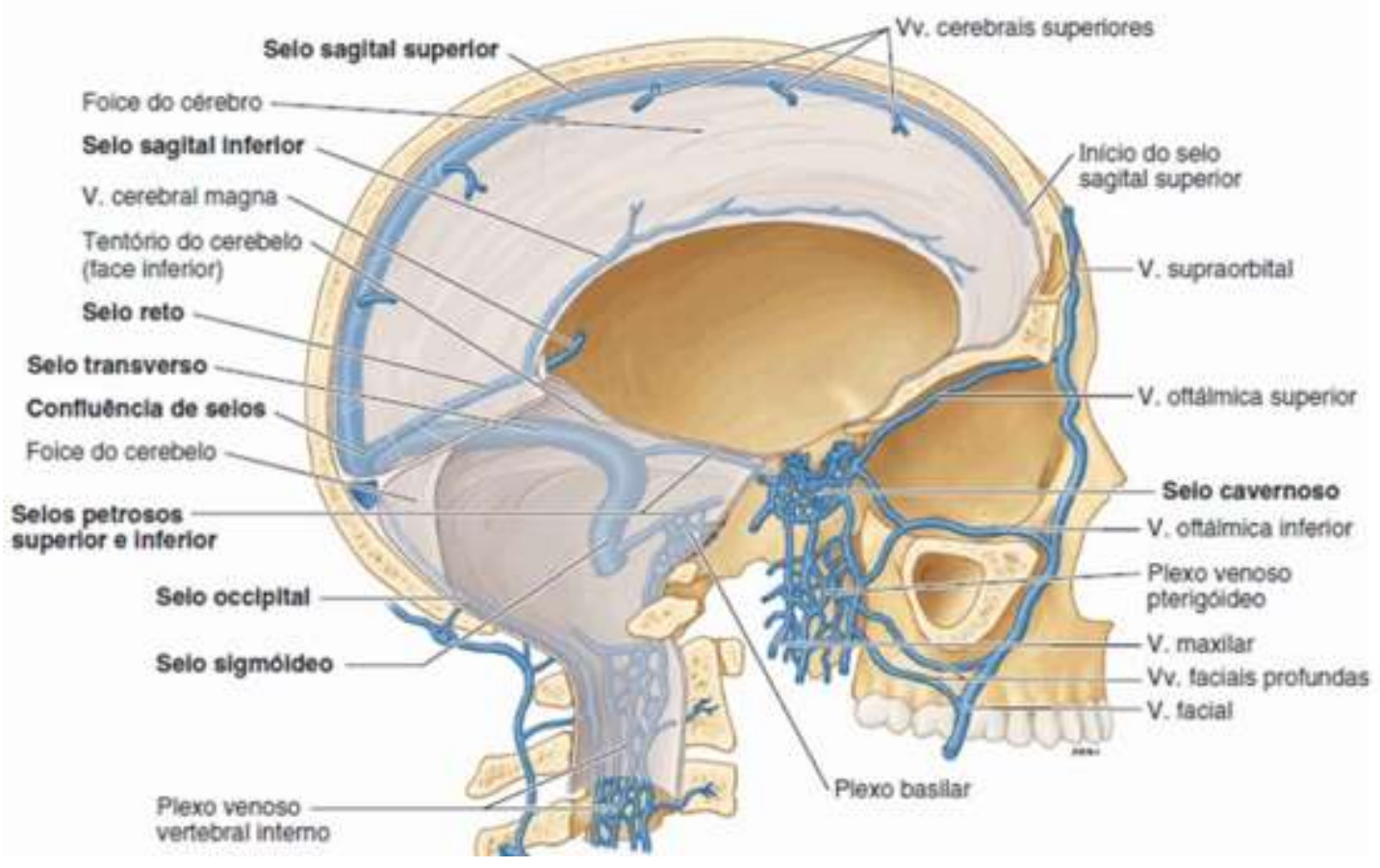

Fonte: Moore (2014).

Os seios venosos da dura-máter também foram estudados em outras espécies de primatas não-humanos e comparados com outros mamíferos. Em Bradypus torquatus e Bradypus variegatus, além dos oito seios venosos observados em Sapajus libidinosus e Saimiri sciureus, foram identificados os seios orbículo-olfatório, para-sagital cerebelar e inter-transverso. A presença destes seios em Bradypus, principalmente do seio orbículo-olfatório pode estar associado ao nicho ecológico deste animal, que tem como principal sentido integrador com o ambiente, o olfato, o que resultaria em uma maior necessidade de suprimento sanguíneo (Ferreira et al., 2005).

De acordo com Swindler e Wood (1973) o seio sagital dorsal, ventral e seio reto estão presentes em Papio, Pan e Homo, assim como em Sapajus. Entretanto, o seio occipital, não observado em Sapajus e Macaca mulatta (Kassell \& Langfitt, 1965), observado apenas em Papio (Swindler \& Wood, 1973).

Em Pan e Homo, o seio petroso superior e seio cavernoso são descritos como conectados ao seio transverso, contudo no Sapajus libidinosus (Pereira et al., 2013) foi descrito apenas a presença do seio transverso. Segundo Swidler \& Wood (1973), em Papio o seio sigmóide não possui a forma tortuosa em forma de S, descrito nas demais espécies, como Pan, Homo e Sapajus. A morfologia da confluência dos seios é descrita como semelhante para Pan, Papio, Homo e Sapajus.

Em Alouatta belzebul, foram observados nove seios, sendo eles: seio sagital dorsal, seio sagital ventral, seio transverso, seio reto, seio sigmoide, seio temporal, seio parietal, seio cavernoso e o seio basilar. Entre os seios venosos observados nesta espécie o seio cavernoso tem sua importância clínica por estar próximo a artéria carótida interna e a glândula hipófise. O seio occipital não foi observado em Alouatta belzebul (Sabec-Pereira et al., 2020), dados que corroboram com os estudos realizados em Macaca mulatta (Kassell \& Langfitt, 1965) e Sapajus libidinosos (Pereira et al., 2013). 


\subsection{Vascularização arterial do sistema nervoso central de primatas humanos e não-humanos}

O estudo da arquitetura vascular do encéfalo de primatas não-humanos é de fundamental importância na compreensão dos mecanismos evolutivos e padrões no comportamento e distribuição dos vasos sanguíneos nestas espécies. A filogenia e a ontogenia dos vasos encefálicos modificam-se em paralelismo com a evolução das exigências funcionais do sistema nervoso central (Tandler, 1898). Com base nesta proposta e em relação ao modelo arquitetônico do suprimento sanguíneo do sistema nervoso central dos animais, estudos filo e ontogênicos, De Vriese (1905), Testut (1911) e Bugge (1974) mostraram claramente que, no processo evolutivo, processam-se modificações cuja tendência é responder as exigências, no sentido de que sistema neural possa desempenhar adequadamente o seu papel. O mecanismo evolutivo não ocorreria se não houvesse uma semelhante adaptação dos padrões vasculares.

Estudos conduzidos por Bugge (1974) e Guerin et al., (1976) discorrem que a complexidade morfológica cerebral é mais ou menos evoluída, e isto se reflete no modelo de suprimento sanguíneo, visto que há dois fatores importantes que devem ser levados em consideração: a regressão do lobo olfatório e o acréscimo de camadas de neocórtex. A respeito de variações de características morfológicas de vasos que compõem o circuito arterial da base do encéfalo, foram estudados em diversos mamíferos temas como a frequência ou não deste circuito, a direção da circulação em áreas funcionais e a pressão do fluxo sanguíneo em relação ao diâmetro dos vasos, além de outros aspectos considerados, como a subdivisão do circuito em dois segmentos: o circuito vértebro basilar e o carótico (Ferreira \& Prada, 2009).

O modelo primata foi estudado no homem por De Vriese (1905) e Testut (1911) com base na classificação de Tandler (1898). A partir de então a literatura científica (Rouviére (1959), Lockhart e Hamilton (1983), Rohen e Yokochi (2002), Machado (2013), trata descrição e ilustração dos sistemas carotídeos e vertebro basilar interligados pelas artérias comunicantes caudais e rostrais, e é dependente do suprimento de sangue via artérias carótidas internas e vertebrais.

O suprimento sanguíneo para o encéfalo de Homo é proveniente de uma circulação anterior (sistema carotídeo) e uma posterior (sistema vértebro-basilar). O círculo arterial do cérebro ou polígono de Willis (Figura 9) é uma rede anastomótica formada pelos ramos desses dois suprimentos arteriais (anterior e posterior) e que se forma na base do encéfalo. As duas artérias cerebrais anteriores, as duas cerebrais médias e as duas cerebrais posteriores se conectam por meio de artérias comunicantes. A artéria comunicante posterior se origina da cerebral posterior e possibilita o fluxo sanguíneo entre a cerebral média e a cerebral posterior. A artéria comunicante anterior possibilita o fluxo entre as artérias cerebrais anteriores de cada um dos hemisférios. Um outro sistema anastomótico também é observado na superfície dos hemisférios pelas três artérias cerebrais, mas não nas regiões mais profundas. Apesar de essa rede anastomótica não ser muito rica, ela pode suprir pequenas interrupções de fluxo para o córtex cerebral, mas não para a substância branca subjacente (Martinez, 2014). 
Figura 9. Vista inferior da base do encéfalo de Homo, para identificação da vascularização arterial.

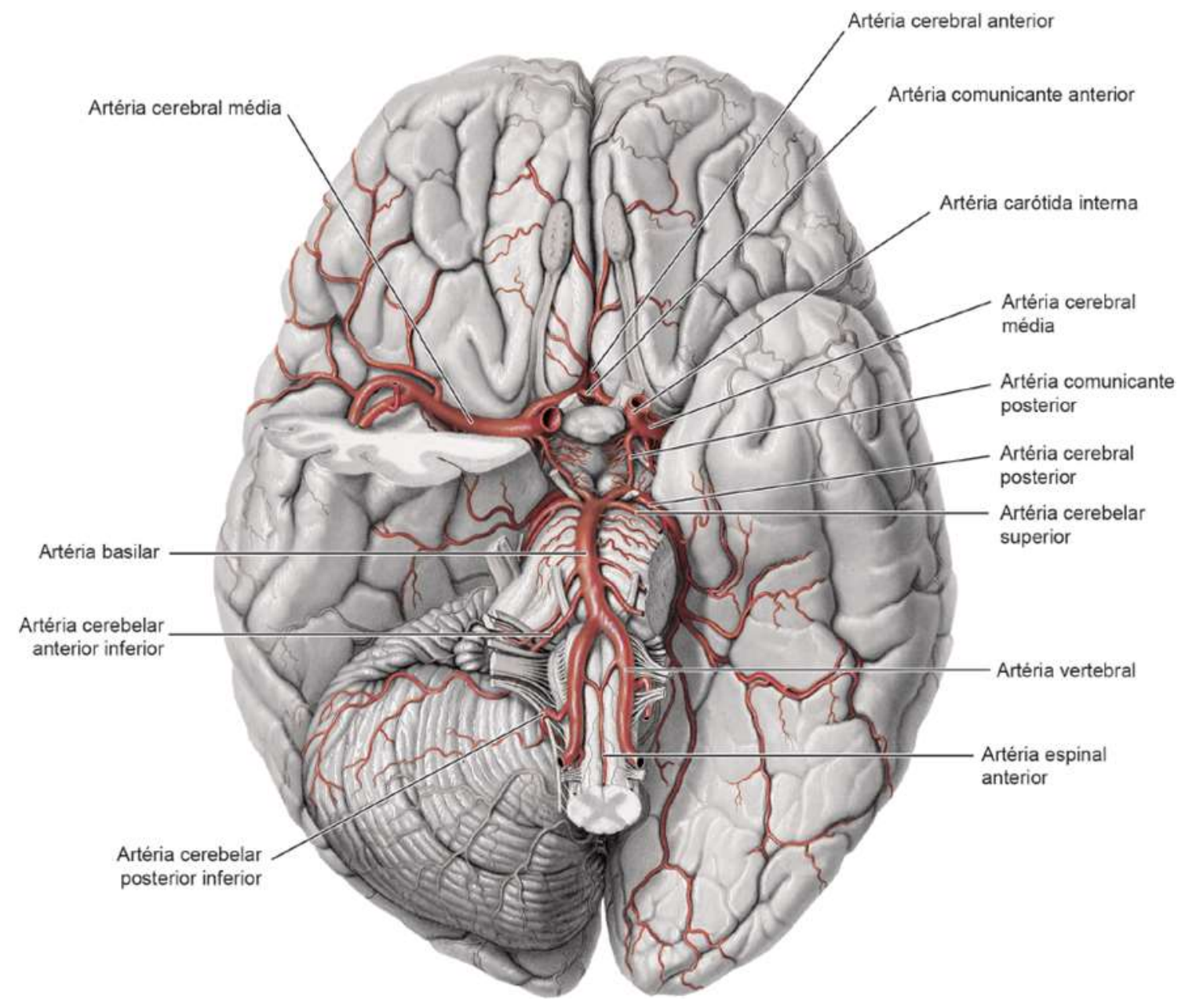

Fonte: Martinez (2014).

O sistema de carótida interna, ramos da bifurcação da carótida comum, após um trajeto mais ou menos longo pelo pescoço, penetra na cavidade craniana pelo canal carotídeo do osso temporal. Em seguida, perfura a dura-máter e a aracnoidemáter e, no início do sulco lateral, divide-se em dois ramos terminais: as artérias cerebrais média e anterior, vascularizando as partes internas das cavidades craniana e a orbita (Meneses, 2011; Machado, 2013; Martinez, 2014.

As artérias carótidas internas apresentam 4 segmentos (Figura 10) com características diferentes, sendo:

1.Segmento cervical, localizado entre a bifurcação da artéria carótida comum até a entrada da ACI no crânio, tem trajeto ascendente junto a partes moles do pescoço. No seu início existe o seio carotídeo (às vezes mais inferior), dilatação localizada que contém nas suas paredes receptores da pressão arterial, e o corpo carotídeo, pequena estrutura sensível a variações da concentração de oxigênio. A artéria carótida interna não dá origem a nenhum ramo nesse segmento e penetra na parte petrosa do osso temporal pelo canal carotídeo (Meneses, 2011).

2.Segmento petroso, a artéria carótida interna fica localizada dentro do osso temporal, apresentando inicialmente um trajeto ascendente vertical; depois de uma inclinação anterior, segue horizontalmente e, a seguir, com uma inclinação superior, novamente se torna ascendente. Dois ramos da artéria carótida interna originam-se nesse segmento: a artéria carotidotimpânica, que irriga a cavidade timpânica, e a artéria pterigóidea, que passa por um canal com o mesmo nome (Meneses, 2011).

3.Ao entrar na fossa média intracraniana, a artéria carótida interna penetra no seio cavernoso, iniciando o segmento cavernoso. A artéria carótida interna forma dentro do seio cavernoso o sifão carotídeo, que diminui o impacto causado pelas pulsações 
arteriais e apresenta 3 ramos principais: tronco meningo-hipofisário, artéria meníngea anterior e um ramo para porção inferior do seio cavernoso. Nesse sifão, a artéria carótida interna tem uma porção vertical, um joelho posterior, uma porção horizontal, um joelho anterior e, finalmente, uma porção vertical, que, ao nível dos processos clinóideos anteriores, sai do seio cavernoso superiormente (Machado, 2013).

4.Segmento intracraniano propriamente dito, a artéria carótida interna passa lateralmente ao nervo óptico, mediaimente ao nervo oculomotor e dá origem aos seus ramos terminais (Machado, 2013).

Figura 10. Vista lateral ilustrativa da artéria carótida interna e seus segmentos.

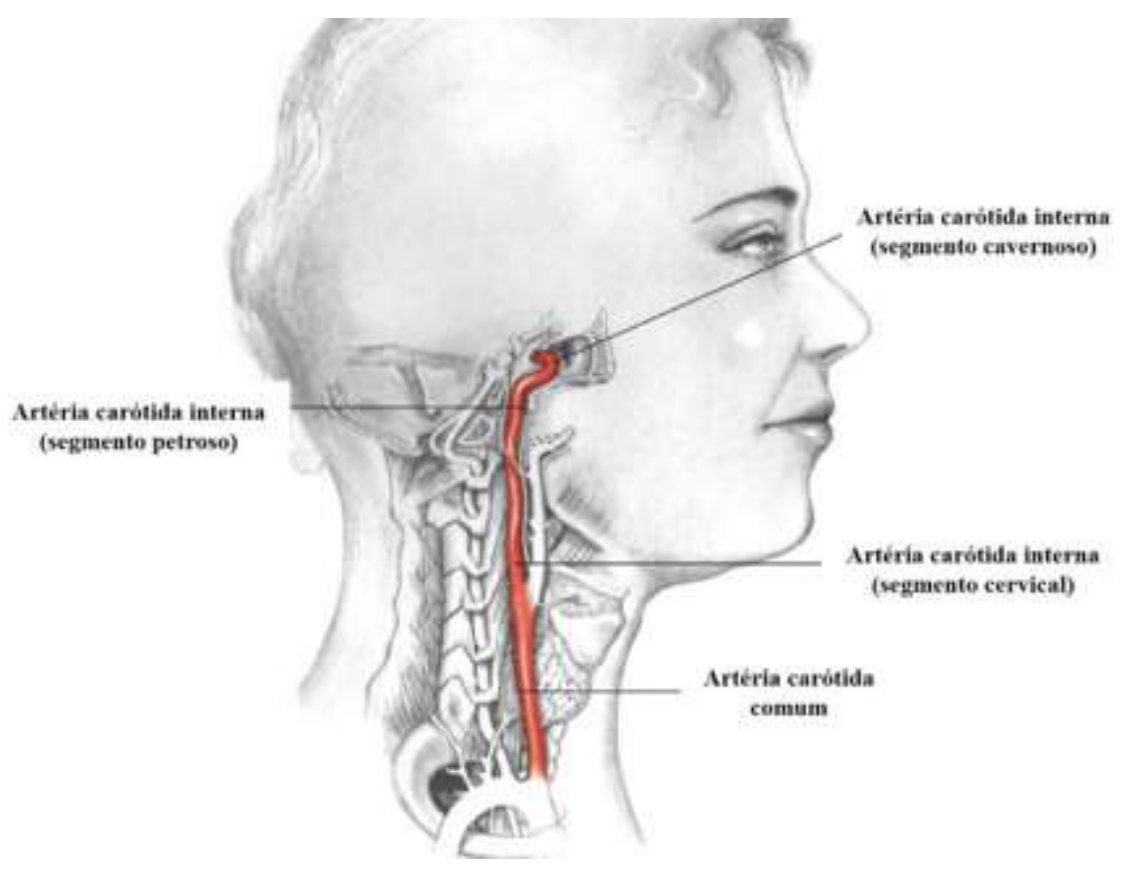

Fonte: Meneses (2011).

Em primatas humanos, o sistema vértebro basilar é derivado da união das 2 artérias vertebrais no nível do sulco bulbopontino, bifurca-se nas artérias cerebrais posteriores na cisterna interpeduncular. No seu trajeto pelo sulco basilar, as artérias pontinas irrigam a face anterior da ponte. Conduzem sangue para estruturas importantes na região posterior do encéfalo de primatas humanos e não-humanos, como o cerebelo, a ponte, o bulbo, o mesencéfalo e estruturas vitais, que regulam a respiração, vigília e sono, o andar, o equilíbrio, os movimentos, a coordenação e a sensibilidade dos braços e pernas, assim como para alguns nervos cranianos responsáveis pela movimentação dos olhos, pela audição, pela fala e pela deglutição (Carneiro, 2004; Afifi \& Bergman, 2008; Martin, 2014).

Em primatas não-humanos a vascularização encefálica apresenta semelhanças aos primatas humanos. Em Alouatta belzebul, primata neotropical, a vascularização encefálica depende de dois sistemas de irrigação: o vértebro-basilar e o carotídeo, onde ocorre uma anastomose de artérias e formam o circuito fechado que supre o encéfalo. As artérias vertebrais do A. belzebul dão origem à artéria basilar, que forma uma ilha arterial na sua origem demostrando uma dupla artéria basilar e que depois segue única em seu trajeto pelo sulco basilar para emitir seu ramo terminal, a artéria cerebral caudal (Sabec-Pereira et al., 2020).

Nesta espécie de primata neotropical a artéria cerebral caudal é subdividida em segmentos arteriais: pré-comunicante e pós-comunicante ao qual exercem a função de suprir as áreas medial e lateral do encéfalo. Sendo assim, a artéria carótida interna direita e esquerda emite ramos terminais, que se anastomosam e fecham a parte rostral do círculo arterial encefálico. Para suprir as áreas pré e pós centrais do córtex encefálico as artérias cerebrais rostrais direita e esquerda dão origem a artéria 
inter-hemisférica que segue seu trajeto pelos hemisférios originando à artéria pericalosa e a artéria calosomarginal. A artéria cerebral média e a artéria cerebral rostral se anastomosam por inoculação direta indicando uniformidade de fluxo. Além disso, em seu trajeto emite vários ramos superficiais para suprir as áreas frontal e temporal do córtex cerebral (Sabec-Pereira et al., 2020).

A artéria carótida interna em Pan (Shellshear 1930), Cereophitecidae e Cebidae (Watts 1934b); Macaca mulatta (Dyrud 1944, Lineback 1961, Weinstein \& Hedges 1962), Gorilla (Raven \& Hill 1950), Homo (Testut \& Latarjet, 1954), Sapajus libidinosus (Ferreira \& Pires 2004; Ferreira \& Prada 2009), Pongo (Watts 1934b) e em Papio ursinus, Cercopithecus pygerithrus e Galago senegalensis (Lake et al. 1990), no segmento intracraniano, segue seu trajeto lateralmente ao nervo óptico e medialmente ao nervo oculomotor. Este vaso dá origem aos seus dois ramos terminais: a artéria cerebral rostral e a artéria cerebral média.

O estudo morfofuncional do sistema nervoso central vem demonstrando aspectos interessantes e pouco explorados, em especial aqueles relativos ao suprimento sanguíneo para o encéfalo. A partir das relações de filogenia e a ontogenia dos modelos arquitetônicos das artérias encefálicas, pode-se observar que não apenas o encéfalo se encontra em processo contínuo de modificações, mas também o arranjo de seus vasos arteriais, caracterizando assim a existência de um paralelismo entre a evolução do sistema nervoso central e as constantes modificações na configuração dos vasos responsáveis por sua vascularização (Lima et al., 2006, Macedo et al., 2014; Aristide et al., 2016).

\section{Considerações Finais}

A literatura anatômica sobre o telencéfalo, a irrigação arterial e os seios venosos da dura-máter de primatas nãohumanos, resulta em apoio para estudos morfológicos, comportamentais, fisiológicos, cirúrgicos e evolutivos. A comparação entre a anatomia de primatas humanos com outros primatas não-humanos propicia uma visão mais detalhada dos fenômenos de convergência e divergência evolutiva no que se refere ao sistema neural. A convergência evolutiva de primatas não-humanos pode servir de base para acessos cirúrgicos, que cada vez mais chegam às clínicas veterinárias necessitados de tratamento sendo que as informações sobre o seu sistema neural ainda são escassas.

\section{Referências}

Afifi, A. K., \& Bergman, R. A. (2008). Neuroanatomia Funcional: texto atlas. 536p.

Aristide, L., Dos Reis, S. F., Machado, A. C., Lima, I., Lopes, R. T., \& Ivan, P. S. (2016). Brain shape convergence in the adaptive radiation of New World monkeys. Proc Natl Acad Sci U S A. 113(8):2158-2163.

Aversi-Ferreira, T. A., Aversi-Ferreira, R. A. G. M. F., Silva, Z., Gouvêa-e-Silva, L. F., \& Penha-Silva, N. (2005). Estudo anatômico de músculos profundos do antebraço de Cebus apella (Linnaeus, 1766). Acta Scientiarum Biological Sciences. 27(3):297-301.

Bicca-Marques, J. C., Silva, V., Gomes, D. F. (2011). Ordem primates. In:Reis N, Perachhi A. L, Pedro W. A, \& Lima I. P, editores. Mamíferos do Brasil, Londrina: Universidade Estadual de Londrina.107-149.

Brandão, M. L. (2004). As bases biológicas do comportamento: introdução à neurociência. Editora Pedagógica e Universitária. 223p.

Broca, P. (2015). Comparative anatomy of the cerebral convolutions: The great limbic lobe and the limbic fissure in the mammalian series. $J$ Comp Neurol. 523(17):2501-54.

Bugge, J. (1974). The cephalic arterial system in insectivores, primates, rodents and lagomorphs, with special reference to the systematic classiication. Acta Anat. 87:1-160.

Bush, E. C., \& Allman, J. M. (2004). The scaling of frontal cortex in primates and carnivores. Proc Natl Acad Sci U S A [Internet].101(11):3962-3966.

Carneiro, M. A. (2004). Atlas e texto de neuroanatomia. Editora Manole Ltda. 278p. 
Chico-Ponce, L. F., Platas-Neri, D., Muñoz-Delgado, J., Santillán-Doherty, A. M., Arenas-Rosas, R., Trejo, D., et al. (2009) Cerebral anatomy of the spider monkey Ateles geoffroyi studied using magnetic resonance imaging.First report: a comparative study with the human brain homo sapiens. Rev Ciencias la Salud.7:10-27.

Colicigno, P. R. C., [et al....]. (2009). Atlas fotográfico de anatomia. Pearson Prentice Hall.334p.

Diniz, L. S. M. (1997). Primatas em Cativeiro: Manejo e Problemas Veterinários. Ícone.196p.

Drake, R. L., et al., [...]. (2011). Gray's: Atlas de Anatomia. Elsevier.557p.

Fernandes, R. J., Pereira, E. R., Pires, V. C. M. C., Melo, F. C. S. A., Melo, F. R., Sabec-Pereira, D. K., \& Pereira, K. F. (2020). Anatomia das vias respiratórias de Alouatta belzebul. Research, Society and Development. (9):11. e5039119927.

Ferreira, J. R., Oliveira, V. L., Oliveira, K. M., \& Oliveira, M. A. (2005). Contribuição ao estudo anatômico da dura-máter do Bradypus torquatus (Linnaeus, 1758) e Bradypus variegatus (Schinz, 1825). Brazilian J Vet Res Anim Sci.42(5):381-7.

Ferreira, J. R., Prada, I. L. S. (2009). O sistema carótico do encéfalo do Cebus apella sp., Linnaeus, 1766. Biota Neotrop. 9(1):285-92.

Godfrey, L. R. (2005). General Anatomy. In: Wolfe-Coote S. The Handbook of Experimental Animals-The laboratory Primate. San Diego: Elsevier Academic Press. 29-43.

Guerin, J., Gouaze, A. \& Lazorthes, G. (1976). Le polygone de Willis de l'enfant et les facteurs de son modelage. Neurochirurgie. 22(3):217-226.

Guimarães, A. B. V. (2007). Reprodução de primatas não-humanos. Rev. Bras. Reprod. Animal. Belo Horizonte. 31(3):339-343.

Kaas, J. H., \& Stepniewska, I. (2016). Evolution of posterior parietal cortex and parietal-frontais networks for specific actions in Primates. J Comp. Neurol. 524(3):595-608.

Kassell, N. F., \& Langfitt, T. W. (1965). Variations in the Circle of Willis in Macaca mulatta. Anatomy Record. 152:257-263.

Kiernan, J. A. (2014). Barr el Sistema Nervioso Humano: Una perspectiva anatómica. Madrid: Ovid Technologies.448p.

Kindlovits, A., \& Kindlovits, L. M. (2009). Clínica e Terapêutica em Primatas Neotropicais. Rio de Janeiro: UFJF. 259p.

Lewitus, E., Kelava, I., Kalinka, A. T., Tomancak, P., \& Huttner, W. B. (2016). Comment on "Cortical folding scales universally with surface area and thickness, not number of neurons." Science. 351(6275):825.

Lima, E. M. M., et al., (...). (2006). Estudo anatômico das artérias da base do encéfalo em gatos (Felis catus domesticus). Jaboticabal: ARS Veterinária. 22(1):01-07.

Lockhart, R. D., Hamilton, O. F., \& Fyfe, F. W. (1983). Anatomia do corpo humano. Guanabara Koogan, 2a ed. 669p.

Lynch, A. J. W., Cortés-Ortiz, L., Di Fiore, A., \& Boubli, J. P. (2015). Special issue: Comparative biogeography of Neotropical primates. Mol Phylogenet Evol.82 (PB):518-29. doi.org/10.1016/j.ympev.2014.09.027.

Macedo, B. C., Branco, É., Pereira, L. C., \& Lima, A. R. (2014). Estudo anatômico do circuito arterial do encéfalo em Eira barbara - relato de dois casos. Biotemas. 27(2):177.

Machado, A. B. (2013). Neuroanatomia Funcional. Rio de Janeiro: Atheneu. 363p.

Marques, K. V., Prada, I. L. S., Silva, Z., \& Liberti, E. A. (2005). Estudo anatômico do tronco encefálico do macaco Cebus apella. Rev Educ Contin em Med Veterinária e Zootec do CRMV-SP [Internet]. 2005. 8(2):156-63.

Martin, J. H. (2014). Neuroanatomia: Texto e Atlas. AMGH Editora.541p.

Martinez, A., Allodi, S., \& Uziel, D. (2014). Neuroanatomia essencial. São Paulo: Grupo GEN-LTC.312p.

Meneses, M. S. (2011). Neuroanatomia aplicada. São Paulo: Grupo Gen- Guanabara Koogan.351p.

Mohedano-Moriano, A., Muñoz-López, M., Sanz-Arigita, E., Pró-Sistiaga, P., Martínez-Marcos, A., \& Legidos-Garcia, M. E., et al., (...). (2015). Prefrontal cortex afferents to the anterior temporal lobe in the Macaca fascicularis monkey. J Comp Neurol. 523(17):2570-98.

Moore, K. L., \& Persaud, T. V. N. (2008). Embriologia clínica. Elsevier.

Moore, K. L. (2014). Anatomia orientada para a clínica. (7a ed.), Guanabara Koogan.

Nickel, R., Schummer, A., \& Seirfele, A. (1981). The viscera of the domestic mammals: The circulatory system, the skin, and cutaneous organs of the domestic mammals. Verlag Pau. Berlin-Hamburg.

Nunes, A. L. V., \& Catão-Dias, J. L. (2014). Primates - primatas do Velho Mundo (Babuíno, Mandril, Chimpanzé, Orangotango). Cubas, Z. S., Silva, J. C. R., Catão-Dias, J. L., editores. In: Tratado de animais selvagens: medicina veterinária. São Paulo: Roca. 378-401.

Pereira, A. S., Shitsuka, D. M., Parreira, F. J. \& Shitsuka, R. (2018). Metodologia da Pesquisa Científica. RS: UFSM, NTE.

Pereira, E. R., Pires, V. C. M. C., Fernandes, R. J., Sabec-Pereira, D. K., Melo, F. R., Schell, R. K. W., Zarpelon-Schutz, A. C., \& Pereira, K. F. (2020). Anatomia do sistema reprodutor feminino de Alouatta belzebul (Linnaeus, 1766). Arq. Bras. Med. Vet. Zootec.72(6):2101-2110. 
Pereira, K. F., Menezes, V. A., \& Araújo, E. G. (2013). Anatomia comparativa da dura-máter de Sapajus libidinosus. Pesquisa Veterinária Brasileira. 33(10):1263-1268

Pereira-de-Paula, J., Prado, Y. C. L., Tomaz, C., \& Aversi-Ferreira, T. A. (2010). Anatomical Study of the Main Sulci and Gyri of the Cebus libidinosus Brain (Rylands). Neurobiologia. 2010.73(2):65-78.

Pissinatti, A., Andrade, M. C. R., Marinho, A. M., \& Ferreira Filho, J. (2010). Uso de primatas em experimentação: histórico. 21-39p.

Ribeiro, A. R. (2006). Aspectos morfológicos da hipófise do macaco Cebus apella. [Tese] São Paulo: Universidade de São Paulo, Faculdade Medicina Veterinária e Zootecnia. 1-89p.

Rohen, J. W., Yokochi, C., \& Lütjen-Drecoll, E. (2002). Anatomia humana. Atlas fotográfico de Anatomia sistêmica e regional. São Paulo: Editora Barueri, 5a ed.

Rylands, A. B, \& Mittermeier, R. A. (2014). Primate taxonomy: species and conservation. Evol Anthropol. 23(1):8-10.

Sabec-Pereira, D. K., Lima, F. C., Melo, F. R., Melo, F. C. S. A., Pereira, K. F., \& Vulcani, V. A. S. (2020). Vascularization of the Alouatta belzebul brain base. Pesq. Vet. Bras. 40(4):315-323.

Sabec-Pereira, D. K., Melo, F. R., Melo, F. C. S. A., Pereira, K. F., \& Vulcani, V. A. S. (2020). Anatomy of the dura mater venous sinus of Alouatta belzebul. Anat Histol Embryol. (00):1-7. https://doi.org/10.1111/ahe.12599.

Sadler, T. W. (2019). Langman, embriologia médica. (13a ed.), Rio de Janeiro: Guanabara Koogan.

Sakai, T., Mikami, A., Suzuki, J., Miyabe-Nishiwaki, T., Matsui, M., Tomonaga, M., et al. (2017). Developmental trajectory of the corpus callosum from infancy to the juvenile stage: Comparative MRI between chimpanzees and humans. PLoS One.12(6):1-22.

Sakka, L., Chazal, J. (2005). The meninges, and anatomical point of view. Morphologie: bulletin de l'Association des anatomistes. Elsevier Masson.35-42p.

Santana, B. E. M. M., Prado, M. R., Lessa, G., Rocha, E. C., \& Melo, F. R. (2008). Densidade, tamanho populacional e abundância dos primatas em um fragmento de floresta atlântica em Minas Gerais, Brasil. Rev Árvore [Internet]. 32(6):1009-117p.

Segantine, A. C. L., Melo, F. C. S. A., Melo, F. R., Schell, R. K., Zarpelon-Schutz, A. C., Sabec-Pereira, D. K., \& Pereira, K. F. (2020). Morfologia do tubo digestório de Alouatta belzebul. Research, Society and Development. (9):10. e5229108930.

Silva, D. N., Oriá, A. P., Araujo, N. L., Martins-Filho, E., Muramoto, C., Libório, F. A., et al. (2017). Morphological study of the eye and adnexa in capuchin monkeys (Sapajus sp.). PLoS One.12(12):1-17.

Snell, R. S. (2003). Neuroanatomia Clínica para estudantes de medicina. Guanabara Koogan.

Souza-Terra, D. R., Sabec-Pereira, D. K., Lima, F. C., Melo, F. C. S. A., Melo, F. R., \& Pereira, K. F. (2018). Anatomy of the spinal cord of Alouatta belzebul. Acta Veterinaria Brasilica. (12)55-61.

Swindler, D. R., \& Wood, C. D. (1973). Atlas of primate gross anatomy: baboon, chimpanzee, and man - Ghent University Library [Internet]. Estados Unidos: Krieger Pub Co. 1-288.

Tandler, J. (1898). Zur Vergleichenden Anatomie der Kopfarterien bei den Mammalia. Denkschrift der Akademie der Wissenschaften, Wien.67:677-784p.

Testut, L. (1911). Traité d'Anatomie Humaine. 6iéme ed. Octave Doin, Paris.944p.

Tilney, F. (1928). The brain from ape to man: a contribution to the study of the evolution and development of the human brain. New York: Paul B. Hoeber Inc. $473 \mathrm{p}$.

Van De Graaff, K. M. (2003). Anatomia Humana. São Paulo: Manole.840 p.

Warwick, R., \& Williams, P. L. (1980). Gray H. Gray's anatomy. Edinburgh: Churchill Livingstone. 